\title{
Clinical Anatomopathological and Therapeutic Aspects of Buschke-Lowenstein Tumor
}

\author{
Kimassoum Rimtebaye ${ }^{1 *}$, Mahamat Ali Mahamat ${ }^{1}$, Freddy Rimtebaye Kimassoum ${ }^{1}$, \\ Frederic Meurde Nemia ${ }^{2}$, Antoinette Djekoundade ${ }^{3}$, Valentin Andjeffa ${ }^{4}$, Valentin Vadandi ${ }^{5}$, \\ Koldjimadje Mingue ${ }^{1}$, Teguil Noar ${ }^{1}$
}

\author{
${ }^{1}$ Urology Department, University Hospital of National Reference, N'Djamena, Chad \\ ${ }^{2}$ Anatomopathology Department, University Hospital of National Reference, N’Djamena, Chad \\ ${ }^{3}$ Dermatology Department, University Hospital of National Reference, N'Djamena, Chad \\ ${ }^{4}$ Traumatology-Orthopedics Department, University Hospital of National Reference, N'Djamena, Chad \\ ${ }^{5}$ University Hospital Center, Abéché, Chad \\ Email: ^rimtebayek@gmail.com
}

How to cite this paper: Rimtebaye, K., Al Mahamat, M., Rimtebaye Kimassoum, F., Meurde Nemia, F., Djekoundade, A., Andjefa, V., Vadandi, V., Mingue, K. and Noar, T. (2021) Clinical Anatomopathological and Therapeutic Aspects of Buschke-Lowenstein Tumor. Open Journal of Urology, 11, 420-426.

https://doi.org/10.4236/oju.2021.1111041

Received: July 2, 2021

Accepted: November 27, 2021

Published: November 30, 2021

Copyright (c) 2021 by author(s) and Scientific Research Publishing Inc. This work is licensed under the Creative Commons Attribution International License (CC BY 4.0).

http://creativecommons.org/licenses/by/4.0/ (c) (i) Open Access

\begin{abstract}
Introduction: Buschke Lowenstein Tumor (BLT) is a tumor, belonging to the group of verrucous carcinomas. It is endowed with an unpredictable potential of recurrence and degeneration. The aim of the work is to present the anatomical and therapeutic characteristics of BLT at the University Hospital of National Reference of N'Djamena in Chad. Patients and Method: Prospective descriptive study of 13 patients with BLT, from May 2009 to April 2019 in the department of urology was included. The patients more than 15, carriers of TBL located at: external genitalia, perineum and anal margin whose clinical, paraclinical assessment allowed the diagnosis of BLT, management and follow-up at the said service. Respect for the patient's identity and consent, the patient's consent is obtained and the anonymity of the photographs is observed. Result: A total of 13 patients had BLT, 11 males and 2 females. The average age of the patients was 32.5 years. The lesions were cauliflower-like and located on the vulva $(n=2)$, the penis, the perineum, the anorectal region in men $(n=11)$. Serology was positive for: $\operatorname{HIV~}(n=3)$, chlamydia $(\mathrm{n}=4)$. The management was surgical by cauterization and excision. Cystoscopy and rectoscope were normal. The cure was obtained in all patients. Two patients had a recurrence at 5 months requiring a second successful cure. Conclusion: BLT is a frequent pathology in the urology department of the University Hospital of National Reference of N'Djamena in Chad. The surgical treatment by "cauterization exeresis" gives a better treatment.
\end{abstract}

\section{Keywords}

Condyloma, Degeneration, Cauliflower, Cauterization-Exeresis, N’Djamena, 
Chad

\section{Introduction}

Buschke Lowenstein Tumor (BLT), also known as giant condyloma acuminata, is a rare tumor belonging to the verrucous carcinoma group with unpredictable recurrence and degeneration potential [1] [2] [3]. Infection usually occurs through sexual contact in patients with decreased immunity or increased estrogen receptors. It can also be transmitted through linen and other soiled materials due to the resistance of the virus in environmental conditions. The lesion was first described by Buschke in 1925 [4]. The lesion is mainly located in the external genitalia, the perineum and the anorectal region in the form of a cauliflower-like, sometimes ulcerated or suppurated tumor. The causative agent is papillomavirus of which serotypes $1,6,16$ and 18 are potentially carcinogenic [5] [6]. Surgical treatment remains effective in spite of the new therapeutic arsenal, notably: $\mathrm{CO}_{2}$ laser, immunotherapy. We report 13 cases of Buschke Lowenstein Tumor treated surgically in the urology department of the University Hospital of N'Djamena in Chad.

\section{Patients and Method}

This was a prospective descriptive study from May 2009 to April 2019 in the department of urology on patients with a tumor located in the sphere of external genitalia and anal margin. Patients over 15 years of age with a tumor located in the external genitalia, perineum and anal margin were included. The clinical and paraclinical workup allowed the diagnosis of Buschke Lowenstein Tumor, which was managed and followed up at the department. The variables were of several kinds. Clinical variables included age, sex, marital status, sexual habits, number of partners, location of the lesion, appearance of the lesion, psychological impact, and history. Paraclinical variables included serology (HIV, Chlamydia and syphilis), blood glucose, creatinine, cyto bacteriological examination of urine, cystoscopy and rectoscopy, and histology of the surgical specimen. The therapeutic and evolutionary variables included: surgery by "cauterization of the exeresis", the use of the urethrovesical probe after the operation (simple or complicated), recurrence, and cure. The consent of the patients was obtained before including them in the study as well as their agreement to use the photographs anonymously and for scientific purposes.

\section{Results}

At the end of the study, 13 patients had met the eligibility criteria. They were 11 men and 2 women. The average age was 32.53 years with extremes of 60 and 19 years. The lesions were cauliflower-like $(\mathrm{n}=8)$ and papillary with sessile base ( $\mathrm{n}$ $=5)$ (Figure 1). The lesions were located on the vulva $(n=2)$ in women in a fat 


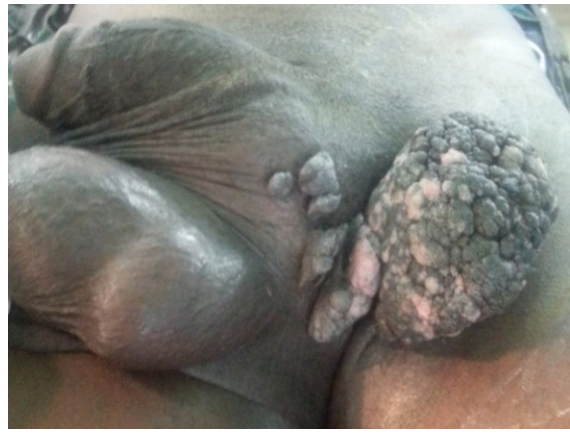

(a)

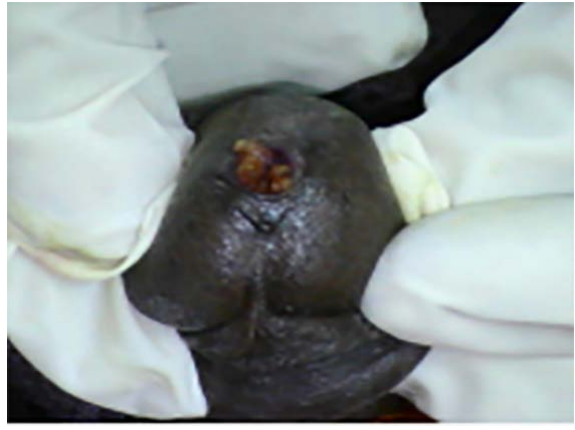

(c)

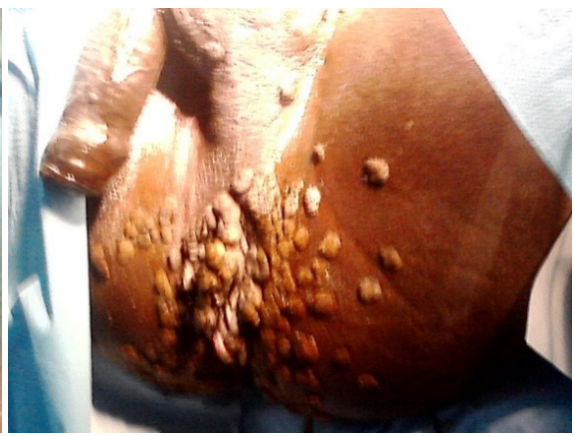

(b)

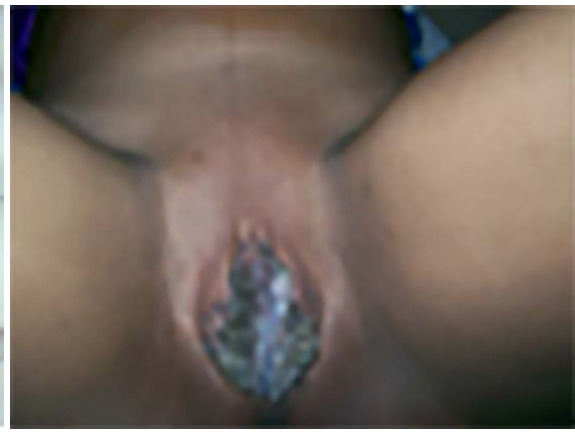

(d)

Figure 1. Different clinical aspects of Buschke Lowenstein tumor.

state and in men, on the urethral meatus $(n=5)$, on the external genitalia, perineum and anal margin $(n=6)$. The average duration between the first observation of the lesion by the patient and the first consultation was 2 years and 8 months with extremes of 6 years and 2 months. The consultation was motivated by the notion of pruritus $(n=13)$, pain during sexual intercourse $(n=7)$, urinary burning $(\mathrm{n}=8)$, worsening of the lesion $(\mathrm{n}=9)$ and fear of a skin "cancer" $(\mathrm{n}=5)$. Serology was positive for: HIV $(\mathrm{n}=3)$, syphilis $(\mathrm{n}=1)$ and chlamydia $(\mathrm{n}$ =4). The Cyto-Bacteriological Examination of the Urines had allowed objectifying an Escherichia Coli infection in 4 cases. Urethrocystoscopy and rectoscopy, which were performed in all patients, allowed to rule out other localizations of the lesion, notably bladder and rectal. Speculum examination in the 2 women invalidated the presence of visible lesions in the vaginal cavity and the uterine cervix. The treatment was surgical (Figure 2) by "cauterization-exeresis" in all patients with a fatty dressing separating the 2 lips of the vulva in the female patients. A ureterovesical catheter was necessary for 7 days in the 5 patients with lesions located in the urethral meatus and in the 2 women with vulvar lesions. The operative parts were sent for histological analysis, the results of which all concluded to be a Buschke Lowenstein tumor (Figure 3). The postoperative course was simple. Two cases of recurrence at 5 months were successfully treated.

\section{Discussion}

For Weaver, Human Papilloma Virus (HPV) infection reaches $80 \%$ of the population over 50 years of age, but only $1 \%$ of women will develop condylomata. For 


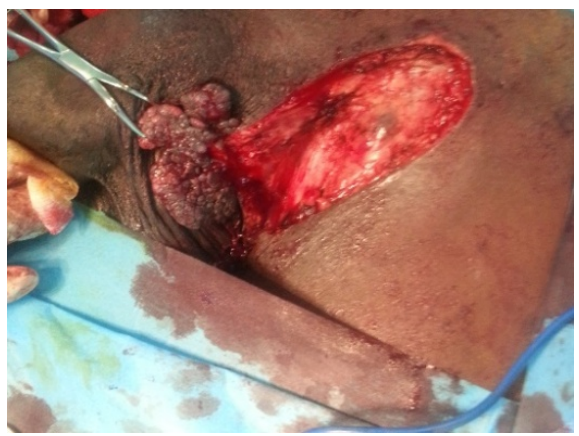

(a)

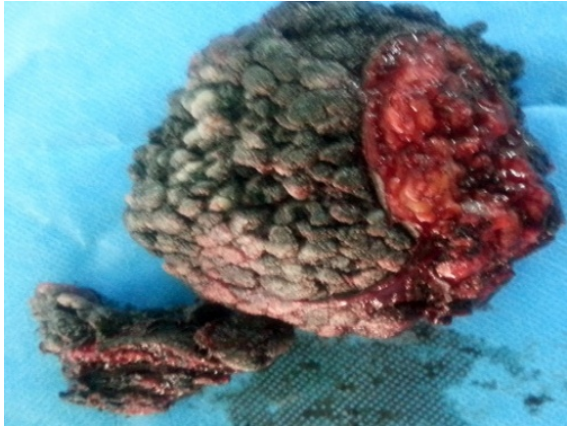

(c)

Figure 2. Surgical images.

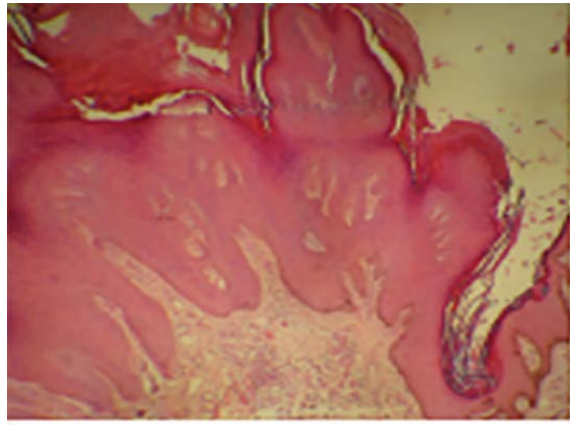

(a)

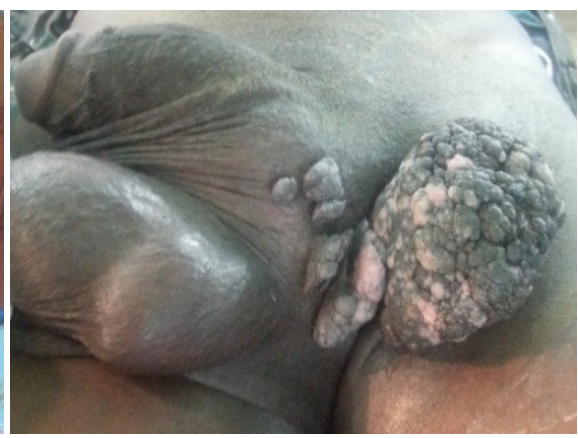

(b)

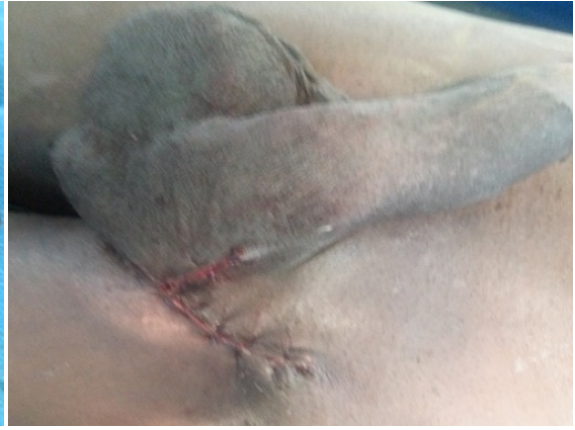

(d)

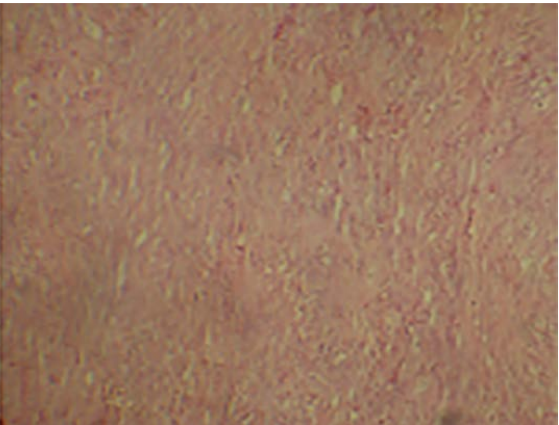

(b)

Figure 3. Anatomopathological images.

El Mejjad only $0.1 \%$ of infected women will develop Buschke Lowenstein Tumor. On the other hand, $80 \%$ of the genitally active adult population has HPV infection, but only $1 \%$ will develop the disease [5] [7]. Serotypes 6, 11, 16 and 18 are the most frequent, however, 16 is more oncogenic compared to the others and the uterine cervical mucosa, which is known to be mechanically and immunologically fragile, seems to be the preferred site for cancerous lesions in women. Multiple risk factors and comorbidity have been reported in the literature, including HIV infection, syphilis, chlamydia, pregnancy, promiscuity, and genital candidiasis. Only three risk factors have been identified: pregnancy in two patients, positive HIV status in another, and a stay in a prison environment. According to Zhenhui [8], transmission is mainly by sexual contact [1] [9] [10], but 
also by linen, gloves and other soiled materials. Mother-to-child transmission can occur in utero through the placenta or during vaginal delivery, justifying the need to examine at birth any newborn child of a mother with a Buschke Lowenstein Tumor lesion. Caesarean section is no longer appropriate in pregnant women with Buschke Lowenstein Tumor as a protective measure for the newborn.

In both patients, the tumor was located in the vulva, had a soft consistency, a sessile base, and a surface finely bristled with bangs about 3 to $8 \mathrm{~mm}$ high and 2 $\mathrm{mm}$ in diameter, giving a cauliflower-like appearance. This cauliflower-like appearance, also described by many authors [11] [12], is psychologically traumatic for the two young pregnant women, aged 18 and 27 years respectively, justifying the urgency of they do not even recognize their sex anymore because of the monstrousness of the lesion. They do not even recognize their sex anymore because of the monstrosity of the lesion. Their main objective is to be cured at all costs before delivery so as not to be humiliated by presenting a vulva of such appearance to the midwives during delivery. In 5 male patients, the tumor, obviously inflammatory, was located in the navicular fossa, with irregularly shaped bangs that emanated like a bouquet of flowers at the urethral meatus. It should be noted that this location makes sexual intercourse difficult because of the trauma and urethrorrhagia that it causes, motivating the consultation and the urgency of the management. As for the 6 patients whose cauliflower lesions were located in the external genitalia, the perineum and the anal margin, apart from the monstrosity of the lesion, it was the fear of a cancerous degeneration of the tumour that motivated their consultation. One of these patients was referred from a prison environment where he had been for 2 years. The promiscuity in the prisons of the place undoubtedly explains the contamination and must be considered as an indicator of decreased immunity.

The natural evolution can be towards; a local invasion, a recurrence or a malignant transformation. For El Mejjad this malignant transformation can reach $8.5 \%$ to $23.8 \%$ in the form of a squamous cell carcinoma. Recurrence, which is always local, single or multiple, poses therapeutic problems, particularly when the excision is limited or incomplete. Only 2 patients presented recurrence at 5 months, justifying a second surgical cure with success. In order to reduce the frequency of recurrence, we decided to perform urethrocystoscopy, rectoscopy and speculum examination to look for other hidden locations that could involve the proximal urethra, bladder, vaginal cavity, cervix and rectum. The absence of localization at these sites explains the good result obtained, in particular the low frequency of recurrence, which was successfully managed at the second surgical cure.

Surgical treatment by "cauterization-exeresis", which we prefer following the example of other authors [1] [9] [11], is associated with precise procedures, in particular: systematic use of a urethrovesical probe to prevent stenosis of the urethral meatus when the localization is meatic and fatty dressings separating 
the edges of the vulva to prevent vulvar synechiae.

Healing is not only physical, but also psychological and even sexual: especially for pregnant patients who are waiting in depression and anxiety for childbirth, for urethral tumor carriers who need to return to normal sexual life and for those who live in fear of cancerous degeneration to be reassured of the benignity of the lesion by the result of the histology

The diagnosis is often based on the clinic for an experienced clinician who easily rules out condyloma planus from secondary syphilis. However, histology is necessary to avoid misdiagnosis of a potential malignant transformation.

\section{Conclusion}

Giant condyloma acuminata or Buschke Lowenstein tumor remains a frequent pathology in the urology department of the CHU-RN of N'Djamena in Chad. Pregnant women with this tumor suffer from nightmarish psychological trauma. Sexual intercourse becomes traumatic for men with a BLT located in the urethral meatus. The reference treatment is surgical, with the aim of obtaining physical and psychological recovery and the resumption of normal sexual activity.

\section{Conflicts of Interest}

The authors declare no conflicts of interest regarding the publication of this paper.

\section{References}

[1] Jdaini, A., Ouraghi, A., El Houmaidi, A., Mhanna, T., Aynaou, M., Irzi, M., et al. (2020) Tumeur de Buschke-Löwenstein : localisation périnéo-scrotale et ano-rectale (à propos d'un cas). PAMJ-Clinical Medicine, 3, Article No. 3. https://www.clinical-medicine.panafrican-med-journal.com/content/article/3/3/full/ https://doi.org/10.11604/pamj-cm.2020.3.3.22456

[2] Ibrahimi, A. and Ziani, I. (2020) Tumeur de Buschke-Lowenstein à localisation pénienne. Pan African Medical Journal, 37, Article No. 19.

https://www.panafrican-med-journal.com/content/article/37/19/full/ https://doi.org/10.11604/pamj.2020.37.19.21024

[3] Vodi, C.C. (2018) tumeur de buschke-lowenstein scrotale : a propos d'une nouvelle observation. Uro' Andro, 1, No. 9.

https://revue-uroandro.org/index.php/uro-andro/article/view/181

[4] Buschke, A. and Löwenstein, L. (1925) Über Carcinomähnliche Condylomata Acuminata des Penis. Klinische Wochenschrift, 4, 1726-1728.

https://doi.org/10.1007/BF01728480

[5] Aubin, F., Pretet, J.-L., Mougin, C. and Riethmuller, D. (2007) Infection à Papillomavirus humains. Annales de Dermatologie et de Vénéréologie, 134, 94-99. https://doi.org/10.1016/S0151-9638(07)89005-3

[6] El Mejjad, A., Dakir, M., Tahiri, M., Attar, H., Cherkaoui, A., Araki, A., et al. (2003) Le condylome acuminé géant-Tumeur de BuschkeLowenstein (à propos de 3 cas). http://www.edream.ma:8080/jspui/handle/123456789/33

[7] Weaver, B.A. (2006) Epidemiology and Natural History of Genital Human Papillo- 
mavirus Infection. Journal of Osteopathic Medicine, 106, S2-S8.

[8] Zhenhui, X., Bakouboula, G., Mabanza, A.J.J. and Bitoky, Y. (1996) condylome acumine et grossesse conduite a tenir a propos d'un cas de condylome géant ou tumeur de buschke-loewenstein. Médecine d’ Afrique Noire, 43, 304-306.

[9] Njoumi, N., Tarchouli, M., Ratbi, M.B., Elochi, M.R., Yamoul, R., Hachi, H., et al. (2013) La tumeur de Buschke-Lowensteinanorectale: à propos de 16 cas et revue de la littérature. The Pan African Medical Journal, 16, Article No. 131.

https://www.ncbi.nlm.nih.gov/pmc/articles/PMC4024435/ https://doi.org/10.11604/pamj.2013.16.131.2864

[10] Ahsaini, M., Tahiri, Y., Tazi, M.F., Elammari, J., Mellas, S., Khallouk, A., et al. (2013) Verrucous Carcinoma Arising in an Extended Giant Condyloma Acuminatum (Buschke-Löwenstein Tumor): A Case Report and Review of the Literature. Journal of Medical Case Reports, 7, Article No. 273. https://doi.org/10.1186/1752-1947-7-273

[11] Rimtebaye, K., DankiSillong, F., Zarif Agah Tashkand, A., Kaboro, M., Niang, L. and Gueye, S.M. (2016) Tumeur de Buschke-Löwenstein: à propos de 8 cas et revue de la littérature. African Journal of Urology, 22, 319-324. https://doi.org/10.1016/j.afju.2016.01.013

[12] Lando, M.J., Mboua, J.N., Tardy, M., Noumsi, N., Nzeuseu, V. and Kouanfack, C. (2004) Affections cutaneo-muqueuses au cours de l'Infection a VIH/SIDA. Clinics in Mother and Child Health, 1, 158-165.

https://www.ajol.info/index.php/cmch/article/view/35804 